a comprehensive analysis using data from primary care. Thorax 2010;65:956-62.

9. McGarvey LP, John M, Anderson JA, et al. Ascertainment of cause-specific mortality in COPD: operations of the TORCH Clinical Endpoint Committee. Thorax 2007;62:411-15.

10. Anthonisen NR, Connett JE, Enright PL, et al. Hospitalizations and mortality in the Lung Health Study. Am J Respir Crit Care Med 2002;166:333-9.

11. Terzano C, Conti V, Di SF, et al. Comorbidity, hospitalization, and mortality in COPD: results from a longitudinal study. Lung 2010;188:321-9.

12. Buajordet I, Ebbesen J, Erikssen J, et al. Fatal adverse drug events: the paradox of drug treatment. J Intern Med 2001;250:327-41.

13. Brekke PH, Omland $\mathrm{T}$, Smith $\mathrm{P}$, et al. Underdiagnosis of myocardial infarction in COPD-Cardiac Infarction Injury Score (CIIS) in patients hospitalised for COPD exacerbation. Respir Med 2008;102:1243-7.

14. Thygesen K, Alpert JS, White HD, et al. Universal definition of myocardial infarction. Circulation 2007;116:2634-53.

15. Korff S, Katus HA, Giannitsis E. Differential diagnosis of elevated troponins. Heart 2006; 92:987-93.

16. Omland T. New features of troponin testing in different clinical settings. J Intern Med 2010:268:207-17.

17. Giannitsis E, Kurz K, Hallermayer K, et al. Analytical validation of a high-sensitivity cardiac troponin T assay. Clin Chem 2010;56:254-61.

18. Omland T, de Lemos JA, Sabatine MS, et al. A sensitive cardiac troponin T assay in stable coronary artery disease. N Engl J Med 2009;361:2538-47.

19. Baillard C, Boussarsar M, Fosse JP, et al. Cardiac troponin I in patients with severe exacerbation of chronic obstructive pulmonary disease. Intensive Care Med 2003;29:584-9

20. Harvey MG, Hancox RJ. Elevation of cardiac troponins in exacerbation of chronic obstructive pulmonary disease. Emerg Med Australas 2004;16:212-15.
21. Fruchter 0, Yigla M. Cardiac troponin-I predicts long-term mortality in chronic obstructive pulmonary disease. COPD 2009;6:155-61.

22. Martins CS, Rodrigues MJ, Miranda VP, et al. Prognostic value of cardiac troponin I in patients with COPD acute exacerbation. Neth J Med 2009;67:341-9.

23. Brekke PH, Omland T, Holmedal SH, et al. Troponin T elevation and long-term mortality after chronic obstructive pulmonary disease exacerbation. Eur Respir J 2008;31:563-70

24. National Collaborating Centre for Chronic Conditions. Chronic obstructive pulmonary disease. National clinical guideline on management of chronic obstructive pulmonary disease in adults in primary and secondary care. Thorax 2004;59/Suppl 1):1-232.

25. Kleinbaum DG, Klein M. Survival Analysis: A Self-Learning Text. New York, USA, 2005: Springer.

26. Bassand JP, Hamm CW, Ardissino D, et al. Guidelines for the diagnosis and treatment of non-ST-segment elevation acute coronary syndromes. Eur Heart $\mathrm{J}$ 2007:28:1598-660.

27. Hawkins NM, Huang Z, Pieper KS, et al. Chronic obstructive pulmonary disease is an independent predictor of death but not atherosclerotic events in patients with myocardial infarction: analysis of the Valsartan in Acute Myocardial Infarction Tria (VALIANT). Eur J Heart Fail 2009;11:292-8.

28. Gottlieb SS, McCarter RJ, Vogel RA. Effect of beta-blockade on mortality among high-risk and low-risk patients after myocardial infarction. $N$ Engl J Med 1998;339:489-97.

29. Salpeter S, Ormiston T, Salpeter E. Cardioselective beta-blockers for chronic obstructive pulmonary disease. Cochrane Database Syst Rev 2005;(4):CD003566.

30. Hoogendoorn M, Hoogenveen RT, Rutten-van Molken MP, et al. Case-fatality of COPD exacerbations: a meta-analysis and statistical modeling approach. Eur Respir $J$ 2011;37:508-15

\title{
Targeted oxygen therapy in the prehospital management of patients with chronic obstructive pulmonary disease
}

Although guidelines recommend targeted oxygen therapy for patients with hypoxia and exacerbations of chronic obstructive pulmonary disease (COPD), there is no strong evidence that this strategy is effective. In this study, Austin and colleagues perform the first randomised controlled trial, in the prehospital setting, of oxygen therapy titrated to target saturations in patients at risk of COPD.

Four hundred and five patients were recruited if upon paramedic assessment they fulfilled criteria for a presumptive diagnosis of COPD. The study suffered from a high level of deviation from the protocol, predominantly administration of high flow oxygen to patients in the titrated oxygen arm. Despite this limitation, intention to treat analysis demonstrated significantly reduced mortality (RR $0.42,95 \%$ CI 0.2 to 0.89 ) in all patients in the titrated oxygen arm, including those later found to have no spirometric evidence of COPD and also in those with confirmed COPD ( $\mathrm{n}=214$ ) (RR $0.22,95 \%$ CI 0.05 to 0.91 ). Those in the titrated oxygen arm with confirmed COPD were also less likely to develop acidosis or hypercapnia. Due to the high rate of deviation on per protocol analysis, power was lost and no mortality benefit was seen.

This study shows that even a relatively short period of high flow oxygen can affect survival in patients at risk of hypercapnic respiratory failure. It also highlights the difficulties in implementing new guidelines as even in the context of a clinical trial less than half the patients received titrated oxygen as per the trial protocol.

- Austin MA, Wills KE, Blizzard L, et al. Effect of high flow oxygen on mortality in chronic obstructive pulmonary disease patients in prehospital setting: randomised controlled trial. BMJ 2010;341:c5462.

\section{William M Ricketts}

Correspondence to Dr William M Ricketts, Research Registrar, Homerton University Hospital, Homerton Row, London E9 6SR, UK; wmricketts@hotmail.com

Published Online First 10 February 2011

Thorax 2011;66:781. doi:10.1136/thx.2011.159434 